\title{
The Research on Character Design Based on the Chinese Mythology: A Case Study of Shisa*
}

\author{
FANG Wen-ting \\ Changzhou Vocational Institute of Mechatronic Technology, Jiangsu, China \\ National Taiwan University of Arts, New Taipei City, Taiwan \\ GAO Ya-juan, LIN Po-hsien, LIN Rung-tai \\ National Taiwan University of Arts, New Taipei City, Taiwan
}

\begin{abstract}
Chinese mythology with its profound cultural asserts and the unconstrained imagination is an indispensable factor in animation creation. The rich resources of myth in ancient China provided a broad space for the creation of animation film and inherited a long ethnic culture. Firstly, the study creates an animation mythological character design model according to the literature review to provide the operational theory for animation design, which consists of three main parts: central idea, research method, and conceptual model. Secondly, the research sums up the animation character creative process framework through the case of Shisa with the specific ideas of creative design. Four steps are used to design a mythological character: set a scenario (illustration), tell a story (interpretation), write a script (reaction), and design a character (reflection). It has analyzed how to integrate the information about the mythology and stimulate the designers' creative imagination in the animation character design in order to create the artworks with unique oriental charm.
\end{abstract}

Keywords: character design, Chinese mythology, Shisa

\section{Introduction}

As the essential component of Chinese culture, Chinese mythology is the manifestation of ethnic heritage and epitome of 5,000 years of history, which offers great resources and inspirations for animation creation and production. Meanwhile, Chinese mythology with its profound cultural asserts and the unconstrained imagination is an indispensable factor in animation creation. Chinese animation had a brilliant moment for Chinese myths and legends, which have deep impact on the development of the domestic animation industry, and being widely used in the creation of animation. Therefore, we can believe that nationalization is the correct development path of the domestic animation industry. Princess Iron Fan of Wan brothers, a new chapter in

\footnotetext{
* Acknowledgements: The authors wish to thank those who contributed to the research, especially, the faculty of National Taiwan University of Arts, Graduate School of Creative Industry Design. This study is modified based on the article of Inheritance and Innovation: A Study of the Animation Character Design Education based on the Chinese Mythology in the Second Asian Conference of Design History and Theory.

FANG Wen-ting, Ph.D. Candicate, Lecturer, Department of Art \& Design, Changzhou Vocational Institute of Mechatronic Technology; Graduate School of Creative Industry Design, National Taiwan University of Arts.

GAO Ya-juan, Ph.D., Lecturer, Graduate School of Creative Industry Design, National Taiwan University of Arts. LIN Po-hsien, Ph.D., Professor, Graduate School of Creative Industry Design, National Taiwan University of Arts. LIN Rung-tai, Ph.D., Professor, Graduate School of Creative Industry Design, National Taiwan University of Arts.
} 
Chinese animation and the animation character combined with cultural traits and social style at the time, wrote an innovative design concept, and provided guidance for contemporary Chinese animation creation. Since 1960s, The Monkey King, Nezha Nao Hai, The Legend of Sealed Book, and The Nine-Colored Deer with artistic means of clay sculpture, paper cutting, ink, etc., adapted from Chinese mythology, had a spectacular success and presented profound cultural connotation with exquisite action designs and elegant colors, which makes unique Chinese charm. The rich resources of myth in ancient China provided a broad space for the creation of animation film and inherited a long ethnic culture. From 1990 to 2000, the once-grand Shanghai Animation Film Studio nearly did not have magnum opus. During this period, Lotus Lantern, Chinese mythological theme inherited the national style, with the basic story about Chen Xiang who saves his mother from God Erh-lang. But in reality, this film applied elements of Hollywood and Japanese animation which had unavoidable flaws in character design. In theory, with the using of mythology, Chinese animation makes us realize consciously that predecessors have made various attempts in building the myth animation character, but how can we make the ancient Chinese myth image deeply integrate into creation, to create a successful animated image of the myth, has become an important subject we need to explore.

In recent years, Europe, America, and Japan are constantly trying to make their animation films to show profound cultural connotations and cultural spirit, and there are some remarkable products. For example, Song of the Sea (2014) was adapted from Irish mythology; Nausicaa of the Valley of the Wind (1984), Princess Mononoke (1999), Laputa Castle in the Sky (1986), and Spirited Away (2002), directed by Hayao Miyazaki, were adapted from Japanese mythology; The Tale of Princess Kaguya (2013) was adapted from the mythological story of Taketori Monogatari, which revealed the cultural identity of different regions and nations. It has been becoming a trend that Hollywood use Chinese elements to make films, such as Hua Mulan (1998) and Kung Fu Panda (2008), but ultimately reflect the American cultural values. Since 2015, the popular Chinese animation films, such as Monkey King, Hero is Back (2015), Monster Hunt (2015), and Big Fish \& Begonia (2016) are all inspired by Shan Hai Jing, the first fantastic book in China. The characters (e.g., the demon king named Huba and faceless villain named Hun Dun), all can find the construction rules from that book. Specifically, the elements of the films show the traditional Chinese culture and deliver the cultural quintessence and endless imagination from the adaptation of mythology, which also confirm that myths and legends have brought infinite creative inspiration and artistic resources for Chinese animation. Marx (Elster, 1968) pointed out that all mythology masters and dominates and sharps the focus of nature in and through the imagination; hence, it disappears as soon as man gains mastery over the focus of nature. Theoretically, the connotation is that myth comes from the nature, the will of human and the beautiful imagination of wisdom, and the mythology will be the creative source of animation creation.

In theory, Chinese mythology is the source of Chinese culture including the unique understanding of life by primitive ancestors, which is the most representative of the national spirit. It shows a relatively broad characteristic of the time comparing the pure religious mythology, as it contains a more active ideological component (Xie, 1997). Nietzsche and Tanner (1994) acknowledged that the idea that myth in turn is the indispensable condition of a culture's "healthy, creative natural power". Human culture cannot be separated from the return and reflection of the myth, which contains culture, art, and science. The Chinese myth is decentralized, so it should be put into a system firstly during the progress of integrate into original animation, to show the complete feature of Chinese myths and related sequence of events. For if a comparison of the mythical form with other cultural forms is taken in a purely objective sense (i.e., based on purely objective 
parallels and connections, it may well lead to a leveling of the intrinsic form of myth (Cassirer, 1965). Langer (1957) provided art is the creation of forms symbolic of human feeling. The concept of mythological images vividly showed by the fictitious animation, which follows traditional and creative imagination, is the transition of emotion. Consequently, combining with mythology and animation will develop a distinctive aesthetic form; the elements of animation, such as rhythm, lens, color, etc., can show the depth of myth diversely and produce a new audio-visual and aesthetic experience by contemporary ideation.

The purpose of this research includes: Firstly, the study will create an animation mythological character design model to provide the operational theory for animation design. Secondly, it will analyze how to integrate the information about the myth art and stimulate the artists' creative imagination in the animation character design in order to create the artistic works with unique oriental charm. Thirdly, the research will sum up the animation character creative process framework through the case of Shisa with the specific ideas of creative design. Designers and artists are the center in the past artistic creation, ignoring the aesthetic experience of the audience, and this article explores the mental model of viewers through the mythological character design, which will help designers to express more acceptable ideas. At last, the research will sum up the experience to innovate in teaching through the analysis of the work of the character design.

\section{Animation Mythological Character Design Model}

How to transfer Chinese mythology into character design has become a critical issue in animation design in this study. An animation mythological character design model facilitating understanding of design creative process is proposed in Figure 1. Animation mythological character design model consists of three main parts: central idea, research method, and conceptual model to systematically analyze the education problems of animation mythological character design, reproducing the most basic creative ideas of character design. The central idea focuses on how to abstract mythological figure from Chinese mythology and then transfer it to a design transformation model to design character creations. The research method consists of three steps: identification, translation, and implementation, to abstract mythological figure from Chinese mythology (identification), transfer them to design information, and design elements (translation), and eventually design a mythological Character (implementation). 


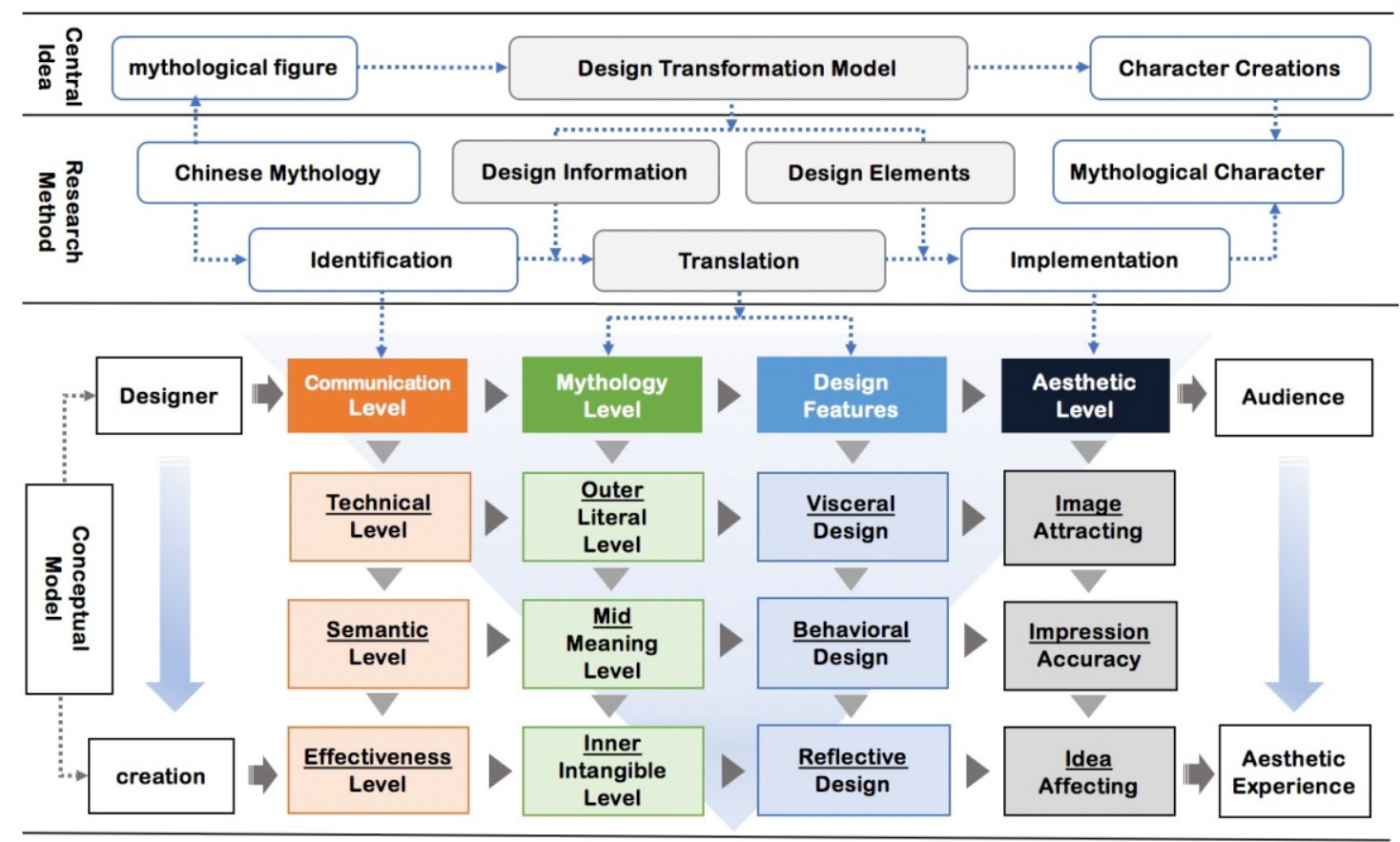

Figure 1. Animation mythological character design model.

Conceptual model has shown the process by the designers' creation artwork, and expresses the thoughts of artwork to audiences, and audiences proceed the aesthetic experience. It consists of four main parts: design level, mythology level, design features, and aesthetic level, which systematically analyze the creative ideas of the mythical character design and the final effect.

\section{Communication Level}

For the communication study, three levels of problems are identified in the study of communication: technical, semantic, and effectiveness (Craig, 1999; Fiske, 2010; Jakobson, 1987). The technical level requires getting the audience's attraction for the recognition through his/her senses, to achieve the image of artistic beauty. The semantic level requires the audience accurately realize the meaning of the message through his/her realization, to achieve the impression of artistic beauty. The effectiveness level concerns the ways in which the audience is made to take the right reflection through his/her affecting, to achieve the idea of artistic beauty.

\section{Mythology Level}

The translation of mythological text requires three aspects: literal level, meaning level, and intangible level. Literal level requires designers to find out creative material about Chinese mythological theory research including the recordation of texts and plastic arts, and summarizes the focus of mythological stories following the historical culture and extracts the core role of myth. Meaning level requires designers to dig essence of connotation and the cream of national culture, and analyzes the mythological quality of roles and modeling features from cultural background, ornamental features, facial features, and character features. Intangible level requires to get the understanding of the text and provide an imagination for the following design to achieve the originality and innovation. 


\section{Design Features}

For emotional design, Norman (2005) proposed three levels of design processing: visceral, behavioral, and reflective design, which represents three kinds of audience's experience that is image, impression, and idea as shown in Figure 2. The visceral design is the most basic feature. Hogarth (1997) explored the six principles as guiding our eyes toward true beauty: fitness, variety, regularity, simplicity, intricacy, and quantity. Six factors can be used as measures of the beauty reflecting the artistic charm in composition, color, rhythm, etc. The behavioral requires designers to attempt in various ways, such as ink painting, single-outline, flat-color image, computer graphics, etc., to enrich the visual beauty of animation and make impressive works. For reflective design, Hegel (1998) pointed out the beauty is characterized as the pure appearance of the idea to sense. Overall, the essence of design is to reach the resonance of the beauty, and designers transform traditional cultures to character design forming special art symbols.

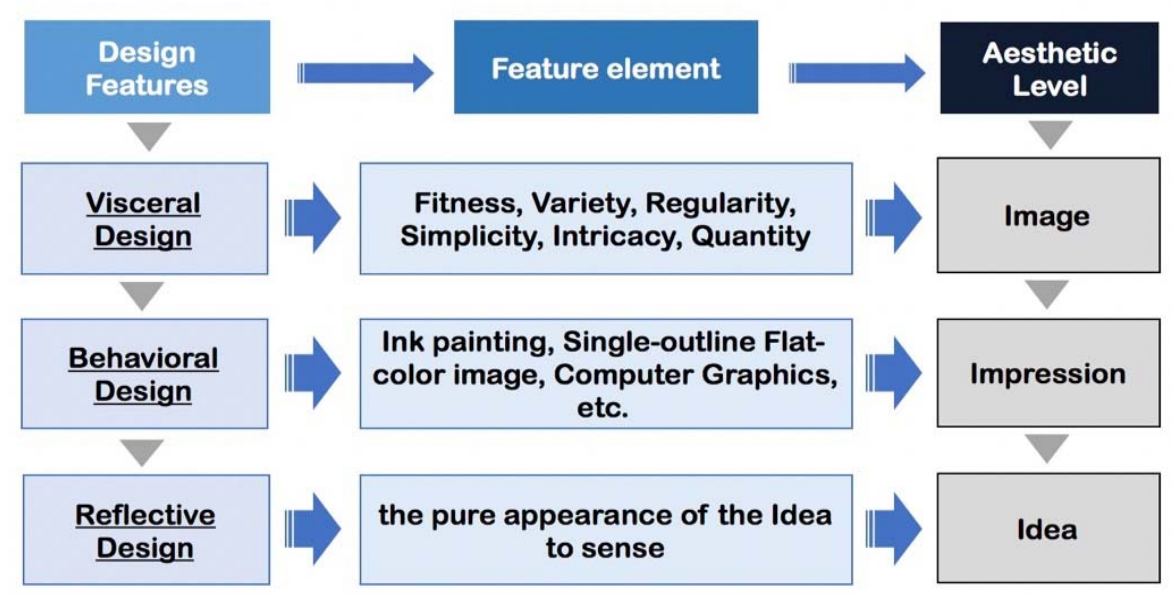

Figure 2. Animation character design features.

\section{Aesthetic Level}

Three levels are identified in the cognitive aesthetics: the image of artistic beauty, the impression of artistic beauty, and the idea of artistic beauty. The image classicalism holds that beauty is in the form of objects; the animation works that intend to achieve the audio-visual beauty for audience must satisfy the image of artistic beauty. Only one answer seems possible and significant form. In each, lines and colors combined in a particular way, certain forms and relations of forms, stir our aesthetic emotions (Bell, 2011). The impression is that every simple idea has a simple impression, which resembles it, and every simple impression has a correspondent idea (Hume, 1740). Overall, it can be seen that the mind perception of human can be divided into two parts (i.e., the impression and the concept). The idea is the way of feelings, emotions, and all other subjective experiences come and go (Langer, 1977). Plotinus (1962) affirmed that it is now time, leaving every object of sense far behind, to contemplate, by a certain ascent, a beauty of a much higher order; a beauty not visible to the corporeal eye, but alone manifest to the brighter eye of the soul, independent of all corporeal aid. Essentially, the beauty of art is the process through the nature to the body and then to the soul of human.

\section{Animation Mythological Character Design-Shisa}

The mythological figure, Shisa, is a research object in this article to explore the theoretical construction, creativity implement, aesthetic experience, etc. Specifically, in a practical design process, four steps are used to 
design a mythological character, for example, set a scenario (illustration), tell a story (interpretation), write a script (reaction), and design a character (reflection) as shown in Figure 3.
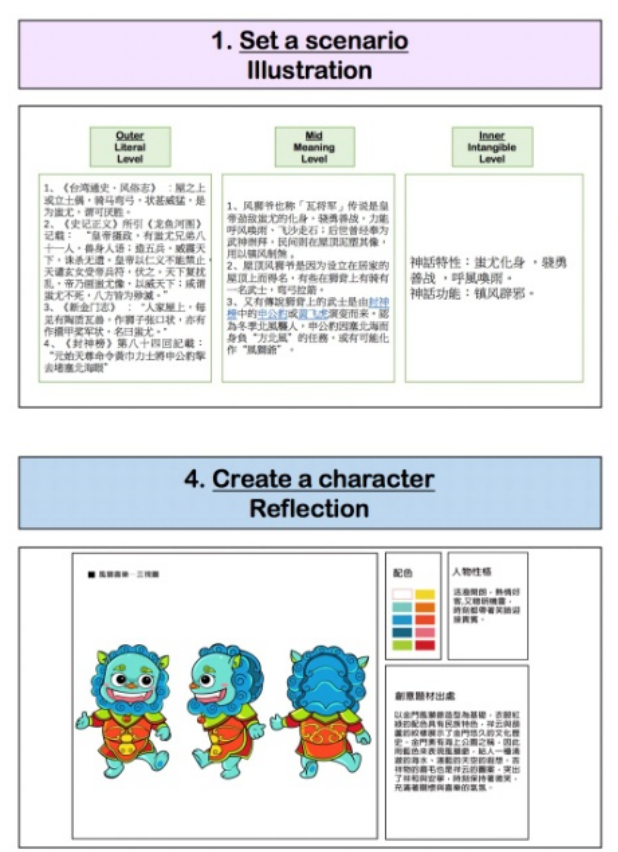
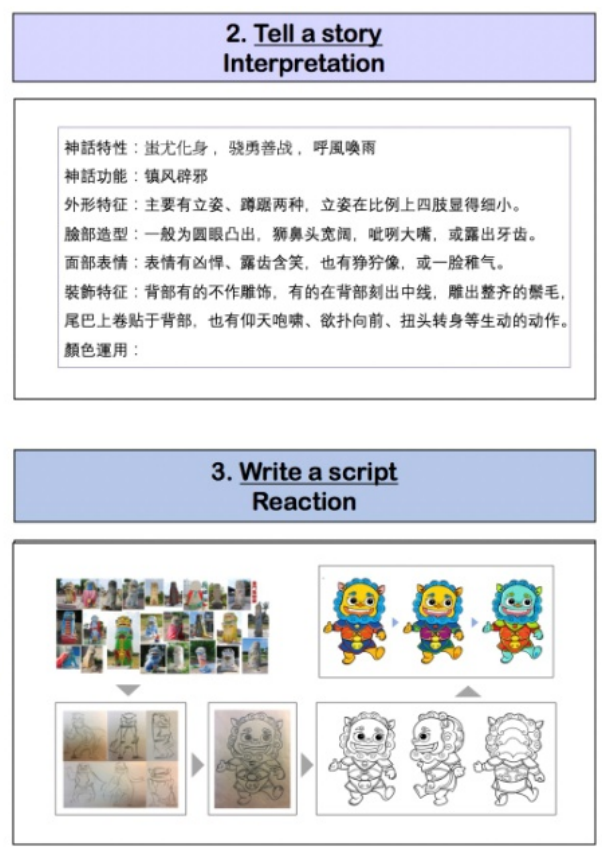

Figure 3. Animation character design process.

\section{Set a Scenario/Illustration}

Based on the investigation data of Chinese antiquity literature, designers must make a systematic analysis of mythology, in terms of extracting the most distinctive features of characters from myth. To clarify the development of the mythology of Shisa and explain the literature connotations, designers deeply explore the origin and the process of historical development. Shisa, also named Tile General, is the embodiment of Chi You (虫尤) who is a vigorous opponent of the Emperor, and he can control the forces of the nature with brave and fierce. Later generations have been regarded as mars to worship and folk sculpture stone statue on the roof to exorcise evil spirits (Xie, 2004). Lian (1983) in History of Taiwan (台湾通史) wrote about there is a clay image on the roof, who rides horse and shoots an arrow from a bow with fierce expression, named Chi You. It is recorded in New Golden Gate (新金门志) that pottery beast on someone's roof, opening his mouth like a lion, looks like as a general, called Chi You (Xu, 1959). According to Longyu Hetu (龙鱼河图), it records that the Emperor acts as regent, and Chi You and his brothers, who have feral bodies and kill the people cruelly, but Emperor cannot forbid him with righteousness, and then, subdue Chi You with runes. The world has not been stable when Chi You died, and Emperor paints the image of Chi You to shock people (Anonymity, 1994). Another legend says that Shisa has evolved from Shen Gongbao or Huang Feihu (黄飞虎) in Feng Shen Yan Yi (封神演义) which is written that Primus orders Shen Gongbao (申公豹) to block the spring of the North Sea with futon (Xu, 2012). In theory, it means that Shen Gongbao may change into Shisa. According to the legend, Shisa is transformed from the wind god, also named Feng Bo or Feng Ye (Xie, 2004).

\section{Tell a Story/Interpretation}

Through the above analysis of the text, collecting the pictures of Shisa in southern Fujian, eastern Guangdong, Taiwan Anping, Ryukyu Islands, and other places, Table 1 summarizes the characteristic of Shisa 
from outside to inside and sums up the basic characteristics of artistic image from mythological feature, mythology function, exterior character, facial shape, facial expression, decorative feature, posture feature, and color style.

Table 1

\section{Basic Characteristics of Shisa}

\begin{tabular}{ll}
\hline Attribution & Basic characteristics \\
\hline 1. Mythological feature & The incarnation of Chi You, brave and fierce, control the forces of nature \\
2. Mythology function & Exorcise evil spirits \\
3. Exterior character & Standing posture and squatting posture, the limbs appear small in the proportion if they stand \\
4. Facial shape & Protruding eyes, wide nose, big mouth, and exposed teeth \\
5. Facial expression & Fierce, ferocious, and laddish \\
6. Decorative feature & Neat mane, tail on the volume \\
7. Posture feature & Roar to the sky, rush forward, turn round \\
8. Color style & Red cloth, emerald green, Rich Huang \\
\hline
\end{tabular}

\section{Write a Script/Reaction}

In terms of the selection of style, it is important to choose the creative expression that is suitable for the character's shape. To produce different aesthetic effects, there are different interpretations about different styles in lines, contours, colors, etc. Indeed, to express the performance of mythology with different design style, it not only conforms to the spiritual needs of viewers, but also can achieve emotional resonance about the interpretation of myth. For artistic style, three styles are attempted in this study: Single-outline Flat-color image, ink painting, and vector style. For different style setting, the sketch has been drawn by designer as research objects. The inspiration of characters comes from the literature analysis, and the creative process follows mythological characteristics. Drawing the draft, essentially, is the process in which designers visualize the memory and the imagination, and is the interpretation of the two previous steps and the abstract generalization of characters as shown in Figure 4.
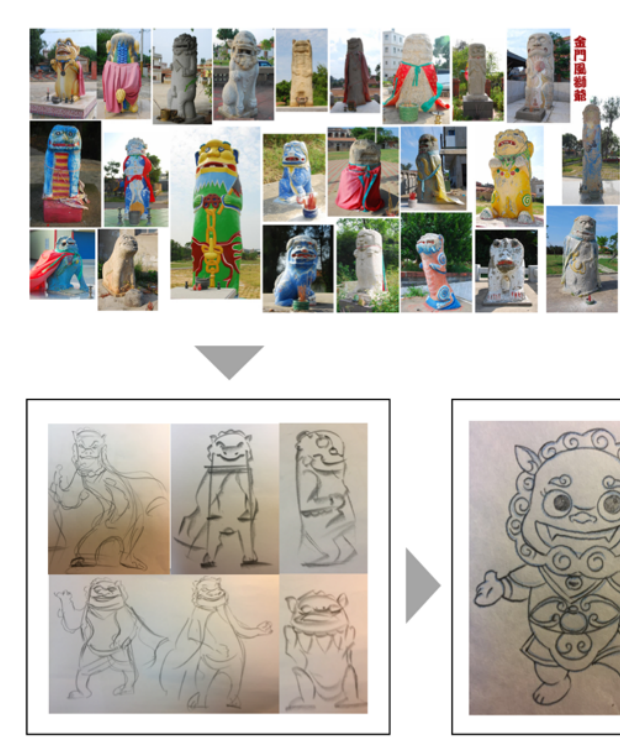
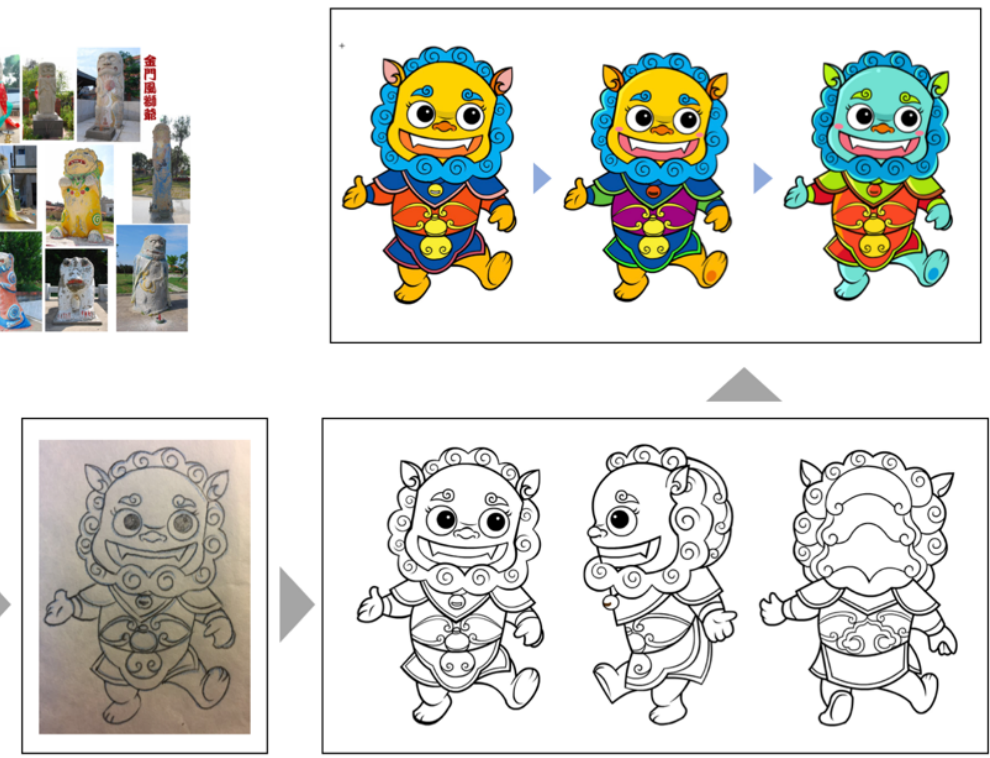

Figure 4. Design sketch (Single-outline flat-color image). 


\section{Create a Character/Reflection}

Theoretically, three different artistic styles have been formed with different symbolic appearance, which means that imagination is eventually created as artworks that brings audience deeply artistic experience. Firstly, Single-outline flat-color image is the most commonly used in animation design. The initial exploration of animation reflects how the vivid form is conveyed by the flowing lines; hence, complex changing lines can create a harmonious animation style. In reality, the Shisa is endowed with flexible and exquisite characteristics by the exaggerated deformation of lines, as shown in Figure 4. Secondly, ink painting is a kind of traditional art forms in China that integrates with the exaggerated characteristics of animation, which has formed an innovative animation language. More precisely, the ink Shisa, an innovative attempt, expresses his texture by the diversified lines as shown in Figure 5. Finally, the color of the vector style of Shisa is mainly red as shown in Figure 6. Adding the modern elements in the original design, such as ties, skateboards, etc., reinvests Shisa with a lively character; adding the cultural elements of cloud pattern conforms to the traditional aesthetic principles.

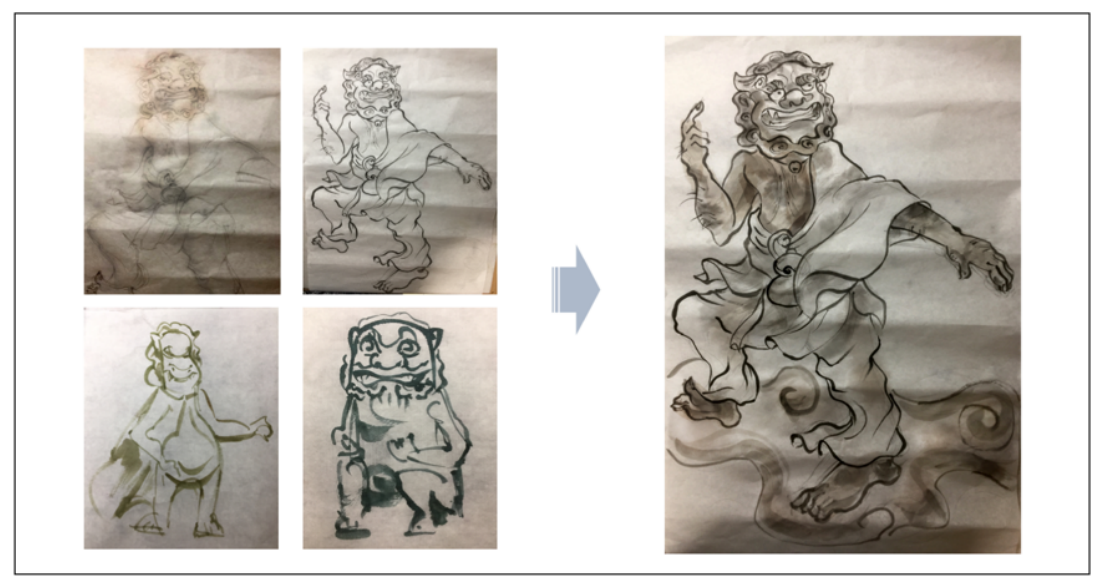

Figure 5. Shisa of ink painting.

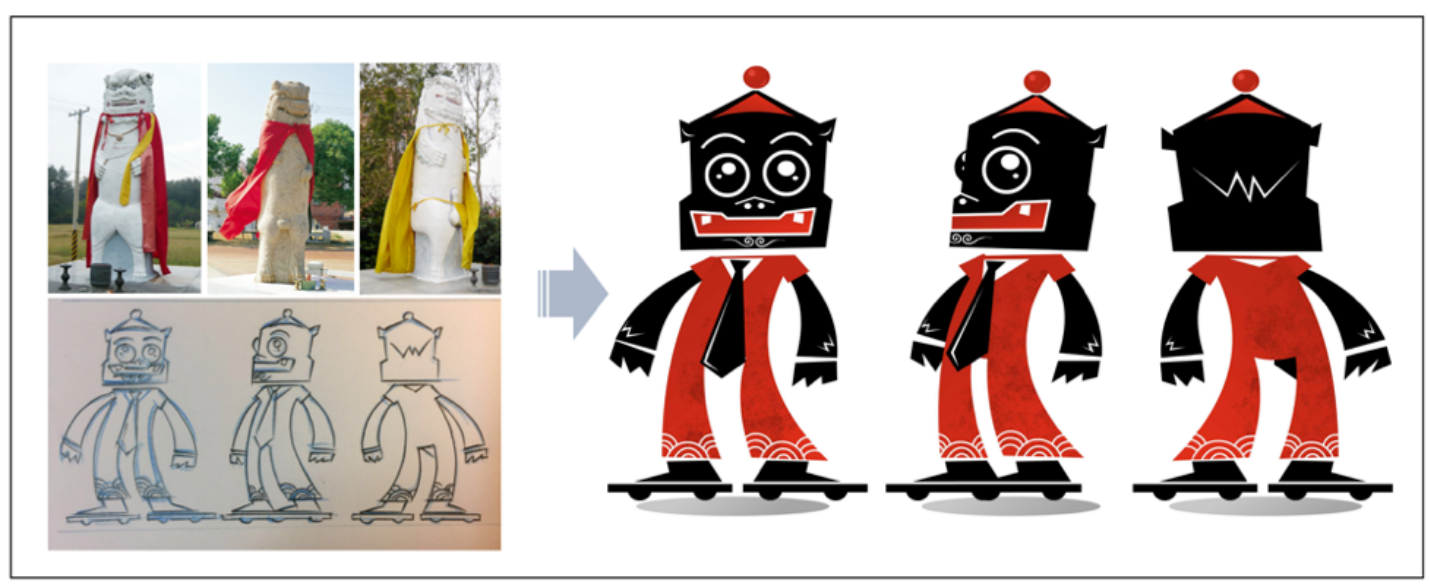

Figure 6. Shisa of vector style with digital painting. 


\section{Results and Discussions}

Combining with animation mythological character design model, the study constructs the animation character creative process framework through the case of Shisa with the specific ideas of creative design. This framework can be used in animation teaching practice from the arrangement of the mythological connotation to the formation of final works, providing a logical creative process, and help designers to carry out innovative research and design as shown in Figure 7.

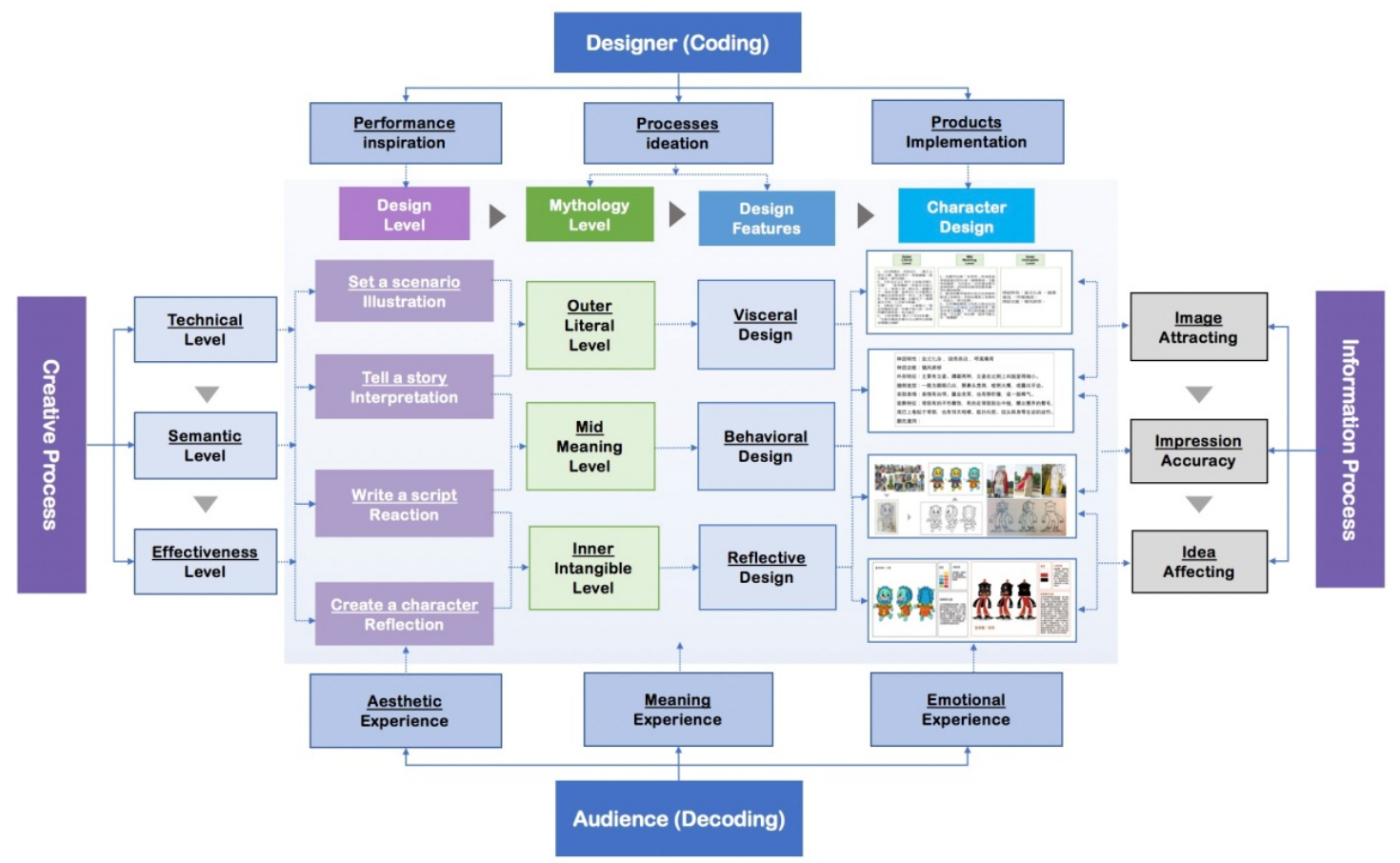

Figure 7. Animation character creative process framework.

For evaluating artworks, the artist involves three key stages to express significance through his/her artworks: performance (inspiration), process (ideation), and product (implementation). Performance is the inspiration to produce a kind of significance that the artist's intentions can be expressed through the artwork. Process represents the artist's ideation that through the artwork, the artist's imagination, thoughts, and feelings can be reproduced. Product is the implementation of signification and expressions which can then be transmitted to the viewer while the artist's and the viewer's thoughts are identical (P. H. Lin et al., 2009; C. L. Lin et al., 2015; R. Lin et al., 2016). We need a better understanding of artist-audience communication not just for taking part in the social context, but also for developing the interactive experience between artist and audience (Goldman, 2004; Trivedi, 2004). For the audience, there are three key stages to feel the beauty of design works: image (attracting), impression (accuracy), and idea (affecting). Accordingly, for creating design works, the framework explains how designers pass the artistic beauty of the animated works to audiences, including design level, mythology level, design features, and character design, and finally, achieve the code of artworks by designers and the decoding of artworks by audiences.

Heidegger (2001) profoundly demonstrated the relationship of art, artist and artwork and explains the essence of art in terms of the concepts of being and truth in The Origin of the Work of Art. If the animation design education can be considered as a whole system, the Chinese mythology is its essence and the designers 
are the core, which conveys the concept of education in the system and integrates the spirit of national culture as shown in Figure 8. In the creative design process, designers transfer imagination, ideas, and emotions to audiences, and audiences produce the understanding of artworks through the deep aesthetic experience, and then audiences will give the feedback to designers. It means that the construction of the model can help educators promote the development of animation education and can change the original educational model (i.e., out of the audience and the market), while designers cannot get the recognition of artworks by audiences if they design behind closed doors. In short, design education is ultimately from designers to audiences, and then, audiences respond to designers. Creative process is a design medium involving cultural thinking, and aesthetic experience is an emotional medium producing cultural understanding. More precisely, design education is the base for the design of original animation.

\section{Conclusions}

For the research of the animation character design based on mythology, it not only helps animation creation enrich the cultural implication, disjointing from superficial expression, but also makes the content of animation infused with national emotion. Meanwhile, Chinese culture and value can be spread incrementally by animation films that possess exaggerated and imaginative expression. As a matter of fact, the inspiration of animation is brought gradually based on the practical creations. To create the classic mythological animation image with the vitality and the artistic value, which is recognized by audience and accepted by market, it requires to have the appropriate creative principles and systematic methodologies to form a mature creative practice. After that, the process of creation will inevitably form the law of artistic creation; systematizing the law can provide theoretical support, comprehensive and effective, for animation design.

But in actuality, the study of Shisa is just the preliminary attempt to create the animation character based on Chinese mythology, which generalizes the animation character creative process framework, and then, analyzes the process that designers design the artwork and audience appreciate the artwork. Surely, this theory is conducive to help designers design animation character with oriental charm, adapting to market conditions, and spread the cultural value and also provides a theoretical exploration for the development of animation design.

\section{References}

Anonymity. (1994). Weft book integration. Shanghai: Shanghai ancient books publishing house.

Bell, C. (2011). Art. New York, NY: CreateSpace Independent Publishing Platform.

Cassirer, E. (1965). The philosophy of symbolic forms: Mythical thought (Vol. 2). New Haven: Yale University Press.

Craig, R. T. (1999). Communication theory as a field. Communication Theory, 9(2), 119-161.

Elster, J. (1968). Karl Marx: A reader. Cambridge: Cambridge University Press.

Fiske, J. (2010). Introduction to communication studies. London: Routledge.

Goldman, A. (2004). Evaluating art. In P. Kivy (Ed.), The Blackwell guide to aesthetics (pp. 93-108). Malden, MA: Blackwell.

Hegel. G. W. F. (1998). Hegel's aesthetics: Lectures on fine art (T. M. Knox, Trans.). Oxford: Oxford University Press.

Heidegger, M. (2001). The origin of the work of art. In R. Kearney, \& D. Rasmussen (Eds.), Continental aesthetics: Romanticism to postmodernism, an anthology (pp. 182-211). Oxford: Wiley-Blackwell.

Hogarth, W., \& Paulson, R. (1997). The analysis of beauty. New Haven: Yale University Press.

Hume, D. (1740). A Treatise of human nature (1967, edition). Oxford: Oxford University Press.

Jakobson, R. (1987). Language in literature. Cambridge: The Belknap Press of Harvard University Press

Langer, S. K. (1957). Problems of art. New York, NY: Charles Scribner's Sons.

Langer, S. K. (1977). Feeling and form. New York, NY: Pearson. 
Lian, H. (1983). History of Taiwan. Beijing: Commercial Press. [in Chinese, semantic translation]

Lin, C. L., Chen, J. L., Chen, S. J. \& Lin, R. (2015). The cognition of turning poetry into painting. Journal of US-China Education Review B, 5(8), 471-487.

Lin, H. (1920). History of Taiwan. Taiwan: Taiwan General History Publishing House.

Lin, R., Hsieh, H. Y., Sun, M. X., \& Gao, Y. J. (2016). From ideality to reality-a case study of Mondrian Style. In International Conference on Cross-Cultural Design (pp. 365-376). Springer International Publishing.

Lin, R., Lin, P. H., Shiao, W. S., \& Lin, S. H. (2009). Cultural aspect of interaction design beyond human-computer Interaction. In International Conference on Internationalization, Design and Global Development (pp. 49-58). Springer Berlin Heidelberg.

Nietzsche, F., \& Tanner, M. (1994). The birth of tragedy: out of the spirit of music (S. Whiteside, Trans.). UK: Penguin Classics. Norman, D. A. (2005). Emotional design: Why we love (or hate) everyday things. New York, NY: Basic books.

Plotinus. (1962). The enneads (S. MacKennam, Trans.). London: Faber and Faber.

Trivedi, S. (2004). Artist-audience communication: Tolstoy reclaimed. The Journal of Aesthetic Education, 38(2), 38-52.

Xie, X. J. (1997). Mythologies and national ethos. Shandong: Shandong Arts Press. [in Chinese, semantic translation]

Xie, Z. R. (2004). National center for traditional arts. Taipei: National Center for Traditional Arts. [in Chinese, semantic translation]

Xu, R. Z. (1959). New golden gate. Kinmen: Kinmen County Government. [in Chinese, semantic translation]

Xu, Z. L. (2007). Fengshen Yanyi. Shanghai: Shanghai People’s Fine Arts Publishing House. [in Chinese, semantic translation] 